\title{
STUDY OF AN EFFECTIVE NON-TRACKING CONCENTRATED SOLAR POWER SYSTEM AS A VIABLE SOLAR THERMAL BIOMASS CONVERSION PROCESS
}

\author{
M. SHAHRIR M. ZAHARI*, SHAHRUL ISMAIL, AND THIRU MANGAI SRINIVASAN \\ Faculty of Technology, Ocean Engineering and Informatic, Universiti Malaysia Terengganu, 21030 Kuala \\ Nerus, Terengganu, Malaysia.
}

*Corresponding author: ${ }^{a}$ shahrir@umt.edu.my

http://doi.org/10.46754/umtjur.2021.04.015

\begin{abstract}
Sunlight is a natural energy source and abundantly available but restricted to certain timeframe and angles depending on the Earth surface where it could be effectively harvest for energy source. Therefore, the purpose of the study is to evaluate the performance of fixed setting systems in comparison to a custom made non-tracking solar concentrator especially in their potential to reach suitable internal temperature ranges required for pyrolysis purpose within a sealed quartz glass reactor as the heat receiver. For the solar collector, six segmented mirrors were placed at varied angles to enable continuous sun ray directed toward one focal spot, at any time of the day without the need for electrical tracking or manually adjusting it based on the sun angle. The parameters in designing the system setup include: Focal Length, Tilt Angle of lens and Azimuth Angles. It is observed that by fixing the focal length to $35 \mathrm{~cm}$ and adjusting the tilt angle of the lens to be fixed at $30^{\circ}$, the reactor was able to achieve the desired temperature range of between 700 to 730 . It can be concluded that the combination of Fresnel lens and simple mirror system were capable of concentrating sunlight into a specific area to reach the desired heating range without the need for complicated, costly equipments.
\end{abstract}

Keywords: Biomass, fresnel lens, solar concentrator, pyrolysis, thermal process

\section{Introduction}

The world energy supply is constantly evolving, heading toward procuring reliable renewable energy sources and clean energy sources such as nuclear power and natural sources to replace the conventional and quite environmentally destructive fossil fuels. It is expected that by the year 2040 , more than $20 \%$ of total energy supply is projected to be coming from renewable sources (Peinado et al., 2019). Among those sources, solar energy is one of the most utilized source of energy and has played an essential role in the overall global transition. After all, the whole planet received about $1000 \mathrm{~W} / \mathrm{m}^{2}$ of solar irradiation in a day (Abdullah et al., 2019) and there is sufficient solar energy in every 1 hour to meet global energy needs for the whole year, making it a particularly attractive solution for reducing energy consumption in buildings and reducing greenhouse gas emissions. (Alamoudi et al., 2019). In 2013 alone, installed global solar power had risen the highest by $35 \%$, while installed wind power increased by $12 \%$ and geothermal and hydro power by less than 5\% (Kannan et al., 2016).

Asian countries such as Malaysia have the highest solar absorption potential being strategically located near the equator. According to Mekhilef et al., (2012), Malaysia's monthly solar irradiation is measured at between 400$600 \mathrm{MJ} / \mathrm{m}^{2}$. During the North-East monsoon, the irradiation becomes higher due to the global wind movement from Central Asia to South China Sea across Malaysia and finally blows from November to March to Australia. Meanwhile, lower irradiation is expected during the South-West Monsoon when the wind direction shifts and travels from Australia to Sumatra Island until entering the Malacca Straits between May and September. This ensures that the environment in Malaysia is ideal for solar energy usage throughout the year. 
Globally, concentrated solar power is widely used in countries such as Egypt, Spain, India, Iran and Italy which utilize mirrors to focus the sunlight; meant for heating-up water into steam and subsequently generate electricity via the steam engine mechanism. Other than for electricity generation, these concentrators are also used in a variety of other applications such as producing heat/steam for reactions within chemical reactors, heating-up gasifiers, or simply to provide the heat required for melting or increasing product temperature (Zeaiter et al., 2015).

In order to generate high enough temperature for those purposes, Sun-based radiation is focused through reflection or refraction using either mirrors or focal points. The mirrors can be arranged in array plane shape called heliostats whilst the focal points can be straightforward focal points or Fresnel focal points (FL). Concentrators are utilized to improve the orientation of sun ray for different applications (Madhugiri et al., 2012) and the commonly used concentrators are the parabolic trough, Fresnel lens and solar tower. Concentrators such as the parabolic dish type are generally bulkier and the temperature rise is slow. In comparison, the Fresnel lens offers high optical efficiency along with minimal weight and low cost (Leutz et al., 2000).

Fresnel lenses consist of a series of concentric grooves etched into holder materials. The lens is useful in many different applications due to its ability of gathering light, lightweight construction, availability in small as well as large sizes, and because they are thinner compared to conventional lenses (Xie et al., 2011). Fresnel lenses are often used in light gathering applications as well as for other components within condenser systems or detector setups, solar pyrolysis and preliminary drying of waste samples. Among multiple real life applications of Fresnel lenses that have been effectively demonstrated were for beaming sunlight into rooms, steam generation, solar cooking, solar heating and desalination (Ullah et al., 2014). Figure 1 below shows the ray diagram of a nonimaging Fresnel lens.

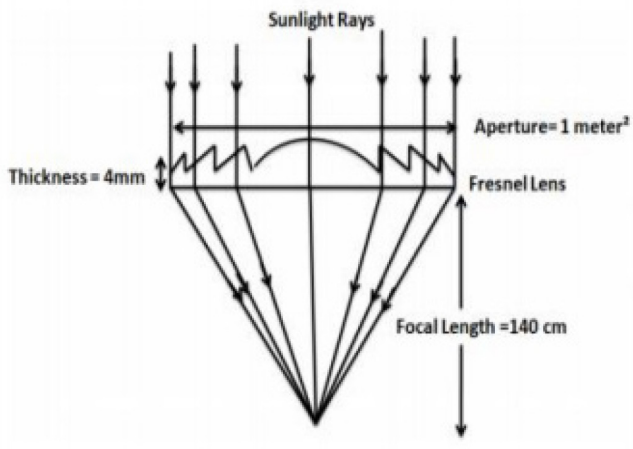

Figure 1: Ray diagram of a non-imaging Fresnel lens

(Source: Gupta et al., 2019)

However, having the lens staying in line with sunlight angle during the day is always necessary to get optimum sunlight radiance over a specific area. To this end, different types of single-axis or dual-axis tracking systems have been developed, based on both mechanical and programmable systems. Evidently, the singleaxis mechanical moving system could only be tests for the azimuth angle only, while the dual- axis tracking device is capable to tracks the sun's movement in the east-west direction and tilts the solar concentrator to utilize the full energy of solar ray during the day (Vu et al., 2016).

Apart from the mechanical and programmable options, a manual way to make use of the solar throughout the day is by installing a non-tracking system using mirrors. Moreover, the non-tracking concentrator is a 
very affordable setup that any individual or organization can afford and build as part of an energy conversion system. However, the challenges of the system is on the positioning of its individual parts to make full use of the solar ray and achieve the desired temperature / energy. The current design of concentrator are mostly focused on a fixed sun focal point instead of the positioning and this resulted in a ranges of temperature (between 200 to $500^{\circ} \mathrm{C}$ ) achieved. Therefore, the designed system can only be used for specific applications that require only low temperature gradients and definitely not capable of being used for thermal conversion of biomass.
The ability to modify the system in order to achieve different temperatures can be an added advantage in designing the concentrator system.

In order to maximize their efficiency, various designs of the solar concentrator were studied and the variation depended on both the geometric shape as well as the place of the pot. There has been a lot of progress in the last four decades involving the nature of the solar concentrator. Some of distinguished designs which have significant contribution to solar technology are as shown in Table 1 below (Madhugiri et al., 2012).

Table 1: Advantages and disadvantages of solar concentrators

\begin{tabular}{|c|c|c|}
\hline Type of Solar Concentrator & Advantage & Disadvantage \\
\hline Parabolic Concentrator & High Concentration & $\begin{array}{l}\text { Larger field of view is required. } \\
\text { Good tracking system is needed. }\end{array}$ \\
\hline $\begin{array}{l}\text { Hyperboloid } \\
\text { Concentrator }\end{array}$ & Compact & $\begin{array}{l}\text { In order to work effectively, a lens } \\
\text { is needed at the entrance aperture }\end{array}$ \\
\hline $\begin{array}{l}\text { Fresnel Concentrator } \\
\text { Lens }\end{array}$ & $\begin{array}{l}\text { Able to separate the direct } \\
\text { and diffuse light - suitable for } \\
\text { controlling of illumination and } \\
\text { temperature of a building interior }\end{array}$ & $\begin{array}{l}\text { Imperfection on the edges } \\
\text { of the facets, causing the rays } \\
\text { improperly focused at the } \\
\text { receiver. }\end{array}$ \\
\hline $\begin{array}{l}\text { Compound Parabolic } \\
\text { Concentrator }\end{array}$ & $\begin{array}{c}\text { Higher gain when its field of } \\
\text { view is narrow }\end{array}$ & $\begin{array}{l}\text { Needs a good tracking } \\
\text { system }\end{array}$ \\
\hline
\end{tabular}

\section{Materials and Methods}

Theoretically, high internal reactor temperature as high as $550^{\circ} \mathrm{C}$ can be reached with an increase in solar irradiation but this temperature would only be able to reach the primary stage of biomass pyrolysis. This is because at about 250 ${ }^{\circ} \mathrm{C}$, the primary pyrolysis stage starts to occur where the biomass solid experiences significant weight loss and it will end at approximately $500^{\circ} \mathrm{C}$, producing the primary products such as water, tar, gases and char. Only at a much higher temperature that all those primary products can further be converted in various secondary reactions into forming the final product which is the bio-oil. It will take a temperature between 500 and $600{ }^{\circ} \mathrm{C}$ for the biomass higher molecular weight components to begin slightly breaking into lighter aromatics and oxygenate but only if they were given time to react. Eventually, the formation of $\mathrm{CO}$, light olefins, and aromatics (from carbohydrates) appears at approximately $700{ }^{\circ} \mathrm{C}$ and at much higher temperatures, the third stage leads to tertiary product (polynuclear aromatics) formation. Figure 2 shows the pathways of pyrolysis products from biomass. 


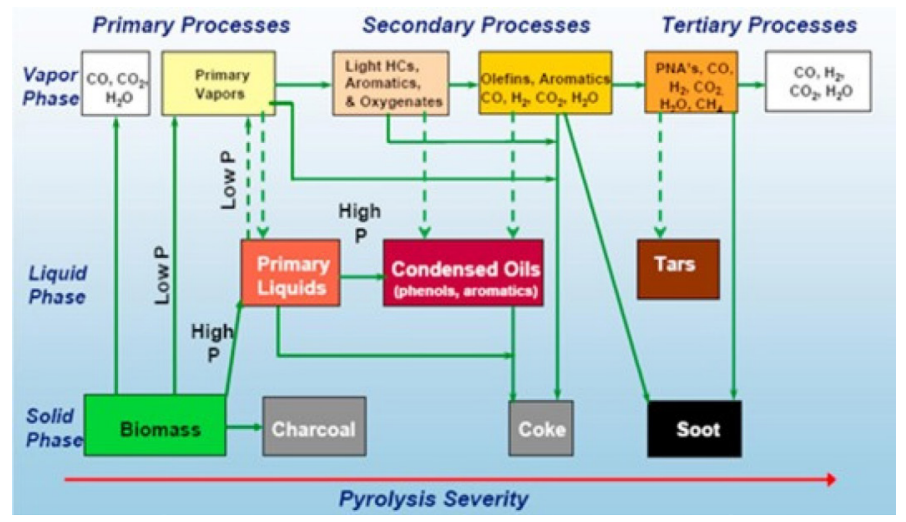

Figure 2: Carbonaceous feedstock pyrolysis pathways

As such, gaining the desired temperature and maintaining the heating process is required. It is logically that the temperature will reach its highest at noon (Gupta et al., 2019). However, the earth rotation and surface location determine the time, place and angle of the sun ray would fall on.

Therefore, in designing the solar concentrator, these parameters that affect the efficiency of the system to concentrate the sunlight at one specific spot will be studied which include focal length, the solar Altitude angle and the Azimuth angle of the Sun as well as on the time variation during the day, the solar irradiance and internal temperature at the receiver end. By definition, the focal length is the distance from the focal point to where collimated input ray combines to a point usually being indicated in term of $\mathrm{f}$-number (or $\mathrm{f} / \#$ ). The solar azimuth angle as well as the solar altitude angle are the other two very important angles in which these two exhibits upon physical parameters for placement on Earth surface with respect to the position of the Sun, and therefore are not influence by the orientation or inclination of the Earth surface. The solar Azimuth angle (A) is the angular displacement from south of beam projection on the Earth horizontal plane. While, the solar Altitude angle (h) is the angle between the horizontal and the line to the sun, in which the angle would be in between $0 \square-$ $90 \square$. The visual description of these angles is as shown in Figure 3.

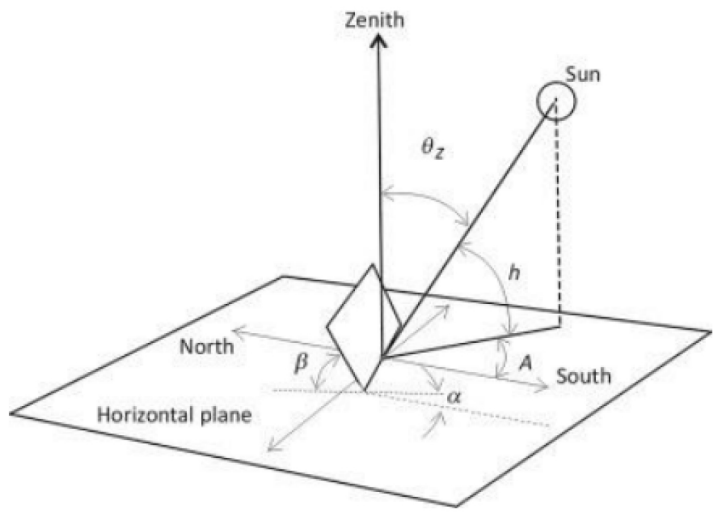

Figure 3: Solar position on sky: Solar azimuth (A), altitude (h) and zenith $(\theta z)$ angles. Surface slope $(\beta)$ and orientation $(\alpha)$ 


\section{Setup A: Development of Fresnel lens Solar Concentrator}

The design of solar concentrator consists of three main parts: the Fresnel lens, the lens holder, and the receiver. The material of the lens is acrylic resin (Poly Methyl-Methacrylate, PMMA) which has a long lifetime under the sunlight, a good transparency in the solar spectrum and a low cost of mass production. Moreover, the refractive index of PMMA is 1.49 which is close to that of glass (Mansour et al., 2005). The aim was to have a lens with a radius of curvature and a concentration ratio as high as possible, in order to minimize the focal length and thus minimize the size of the solar rig.

In order to provide an elevation above the ground for the lens, the lens holder will be designed and constructed to fit the specific Fresnel lens. The elevation is measured from the receiver to the surface of the lens. The design of the lens holder is chosen to act like a scissor lift, in order to offer the option to adjust the height of the lens from the ground according to the required temperature. In order for the lens to fit in properly, the dimension of the lens holder will have to be a slightly longer. In that configuration, the maximum power of concentration or heating was achieved by adjusting the lens holder to gain a desired distance between the lens and the receiver which would be equal to the focal length. Therefore, the length of the arms of the lens holder was chosen to be designed in a way that it is higher than the focal length for appropriate manual adjustment. It would also enable modification to obtain a beam of a wider surface area; which would be beneficial to spread the heat more evenly on the surface of the receiver, just merely by shortening the elevation of the lens.

The receiver is the part of the apparatus that will be designed to absorb the radiant energy out of the lens and conduct the heat energy until a satisfying temperature is reached. The receiver is in cylindrical shape and it is made of Quartz glass with a measurement of $30 \mathrm{~cm}$ long and a diameter of $5 \mathrm{~cm}$. It is made out of quartz glass that has a high melting point and low thermal expansion coefficient. Since the material is also practically immune to sudden temperature changes, it would be able to retain the heat much better than other objects. For internal temperature measurement purposes within the glass tube, Empty Fruit Bunch (EFB) as the biomass sample will be placed in the receiver. One end of the receiver will be connected to a thermocouple connected to an Arduino setup in order to measure the temperature of the sample in the receiver. Meanwhile, the other end of the tube is connected to a vacuum pump to suck out air from the receiver vessel to prevent any pressure build-up with the receiver vessel. The dryness and properties of the EFB Sample is measured to test the performance of the system for biomass thermal conversion process.

\section{Setup B: Development of the non-tracking system for the Fresnel Lens Solar Concentrator}

A combination of Fresnel lens and six segmented mirrors that are arranged symmetrically to each other is used to develop a non- tracking solar concentrator system. The symmetrical arrangement helps to redirect the sunlight rays into a small area of spot size $50 \mathrm{~cm}^{2}$ in order to be used for common solar thermal. Concentrated sunlight is then reflected through segmented mirrors and focused on the receiver which then gets heated.

Segmented mirror system is arranged in different orientations for the design. These mirrors are made up of $0.8 \mathrm{~mm}$ thick aluminum sheets that have mirror polishing on the front side of it and this sheet is then pasted on a $1.5 \mathrm{~mm}$ thick Galvanized Iron (GI) sheet. Unlike any silica mirror, this mirror is supposedly able to sustain high temperature without any bending or breaking. The size of each mirror sheet is $20 \mathrm{~cm}$ wide and $70 \mathrm{~cm}$ long. The mirrors are placed at various angles, and light is redirected into a specific position on the receiving vessel. A mechanical platform is custom-made for mounting all the mirrors in one setting, with the angle adjusted for each mirror as it is attached onto the main frame. Six segmented mirrors are placed at varied angles that would enable the 
system to continually focus the sun ray to one spot, at any time of the day without the need for tracking or adjusting it based on the sun angles. This arrangement would enable continuous solar heating during the whole day while the lens remains stagnant.

The addition of mirrors to the system would enable adjustment for the different sun angle during the day and allow it to focus the sunlight by controlling the mirror tilt angle. Tilt angle is defined as the line that is perpendicular to the axis as the normal line and the angle between the normal line and the incidence light. The large tilt angle will lead to a large refraction and cause the light to diffuse. Positively, increasing the tilt angle will cause the focal area to deviate from the initial position causing the focal length to become shorter (Zheng, 2017)

\section{Results and Discussion}

In order to obtain high temperature in the receiver a few parameters were modified. The effect of the solar irradiance and the time variation of the day were observed to attain high temperature. The data obtained for the parameters for Setup A is as shown in Table 2.

Table 2: Data obtained from field experiment for Setup A

\begin{tabular}{|c|c|c|c|c|}
\hline Time & Focal Length (cm) & Tilt Angle $\left({ }^{\circ}\right)$ & Solar Irradiance $\left(\mathbf{w} / \mathbf{m}^{2}\right)$ & Temp. $\left({ }^{\circ} \mathbf{C}\right)$ \\
\hline 11:00:09 AM & 32 & 45 & 874 & 350 \\
\hline 11:03:09 AM & 32 & 45 & 878 & 353 \\
\hline 11:06:09 AM & 32 & 45 & 879 & 347.5 \\
\hline 11:09:09 AM & 32 & 45 & 878 & 352 \\
\hline 11:12:09 AM & 32 & 45 & 877 & 350.5 \\
\hline 11:15:09 AM & 32 & 45 & 881 & 362 \\
\hline 11:18:09 AM & 32 & 45 & 884 & 364.25 \\
\hline 11:21:09 AM & 32 & 45 & 885 & 369 \\
\hline 11:24:09 AM & 32 & 45 & 883 & 304.5 \\
\hline 11:27:09 AM & 30 & 45 & 887 & 246.75 \\
\hline 11:30:09 AM & 30 & 40 & 890 & 449.5 \\
\hline 11:33:09 AM & 30 & 40 & 890 & 401.75 \\
\hline 11:36:09 AM & 30 & 40 & 895 & 338 \\
\hline 11:39:09 AM & 30 & 40 & 894 & 214.75 \\
\hline 11:42:09 AM & 30 & 40 & 895 & 221.25 \\
\hline 11:45:09 AM & 30 & 40 & 897 & 403.75 \\
\hline 11:48:09 AM & 30 & 40 & 894 & 443 \\
\hline 11:51:09 AM & 30 & 40 & 896 & 436.5 \\
\hline 11:54:09 AM & 30 & 40 & 898 & 484 \\
\hline 11:57:09 AM & 30 & 40 & 899 & 439 \\
\hline 12:00:09 PM & 30 & 40 & 897 & 499 \\
\hline 12:03:09 PM & 30 & 40 & 896 & 450.25 \\
\hline 12:06:09 PM & 30 & 40 & 891 & 430.75 \\
\hline 12:09:09 PM & 28 & 40 & 892 & 430.75 \\
\hline 12:12:09 PM & 28 & 40 & 887 & 421.75 \\
\hline
\end{tabular}




\begin{tabular}{|c|c|c|c|c|}
\hline 12:15:09 PM & 28 & 35 & 889 & 374 \\
\hline 12:18:09 PM & 28 & 35 & 890 & 308.25 \\
\hline 12:21:09 PM & 28 & 35 & 902 & 244.25 \\
\hline 12:24:09 PM & 28 & 35 & 899 & 195.5 \\
\hline 12:27:09 PM & 28 & 35 & 897 & 190 \\
\hline 12:30:09 PM & 28 & 35 & 893 & 183.5 \\
\hline 12:33:09 PM & 28 & 35 & 899 & 166.5 \\
\hline 12:36:09 PM & 28 & 35 & 903 & 178 \\
\hline 12:39:09 PM & 28 & 35 & 905 & 197.5 \\
\hline 12:42:09 PM & 28 & 30 & 899 & 229.25 \\
\hline 12:45:09 PM & 30 & 30 & 900 & 342 \\
\hline 12:48:09 PM & 30 & 30 & 899 & 345 \\
\hline 12:51:09 PM & 30 & 30 & 895 & 418.5 \\
\hline 12:54:09 PM & 30 & 30 & 899 & 439.5 \\
\hline 12:57:09 PM & 30 & 30 & 903 & 459.5 \\
\hline 13:00:09 PM & 30 & 30 & 903 & 454.25 \\
\hline 13:03:09 PM & 30 & 30 & 897 & 393 \\
\hline 13:06:09 PM & 30 & 30 & 894 & 388.5 \\
\hline 13:09:09 PM & 30 & 30 & 902 & 437 \\
\hline 13:12:09 PM & 29 & 30 & 899 & 399 \\
\hline 13:15:09 PM & 29 & 25 & 896 & 197.75 \\
\hline 13:18:09 PM & 29 & 25 & 899 & 392.5 \\
\hline 13:21:09 PM & 29 & 25 & 904 & 365.5 \\
\hline 13:24:09 PM & 29 & 25 & 902 & 175.5 \\
\hline 13:27:09 PM & 29 & 25 & 903 & 135.5 \\
\hline 13:30:09 PM & 29 & 25 & 899 & 112.75 \\
\hline 13:33:09 PM & 29 & 25 & 899 & 137.5 \\
\hline 13:36:09 PM & 29 & 25 & 858 & 106.25 \\
\hline 13:39:09 PM & 29 & 25 & 899 & 174 \\
\hline 13:42:09 PM & 29 & 25 & 895 & 268 \\
\hline 13:45:09 PM & 29 & 25 & 905 & 262 \\
\hline 13:48:09 PM & 29 & 25 & 899 & 158.75 \\
\hline 13:51:09 PM & 29 & 25 & 903 & 155.25 \\
\hline 13:54:09 PM & 29 & 25 & 899 & 152.75 \\
\hline 13:57:09 PM & 29 & 25 & 899 & 151.25 \\
\hline 14:00:09 PM & 30 & 35 & 904 & 228 \\
\hline 14:03:09 PM & 30 & 35 & 896 & 247.25 \\
\hline 14:06:09 PM & 30 & 35 & 900 & 268.5 \\
\hline 14:09:09 PM & 30 & 35 & 902 & 282.5 \\
\hline
\end{tabular}




\begin{tabular}{|c|c|c|c|c|}
\hline 14:12:09 PM & 30 & 35 & 898 & 333.25 \\
\hline 14:15:09 PM & 30 & 35 & 901 & 399 \\
\hline 14:18:09 PM & 30 & 35 & 905 & 451.75 \\
\hline 14:21:09 PM & 30 & 35 & 901 & 478.75 \\
\hline 14:24:09 PM & 30 & 35 & 903 & 429.25 \\
\hline 14:27:09 PM & 30 & 30 & 899 & 398 \\
\hline 14:30:09 PM & 30 & 30 & 907 & 457.75 \\
\hline 14:33:09 PM & 30 & 30 & 881 & 318.5 \\
\hline 14:36:09 PM & 28 & 30 & 894 & 271.25 \\
\hline 14:39:09 PM & 28 & 30 & 872 & 214 \\
\hline 14:42:09 PM & 28 & 30 & 908 & 256.75 \\
\hline 14:45:09 PM & 28 & 30 & 899 & 384.75 \\
\hline 14:48:09 PM & 30 & 35 & 906 & 420.25 \\
\hline 14:51:09 PM & 30 & 35 & 897 & 412.5 \\
\hline 14:54:09 PM & 30 & 35 & 912 & 485.25 \\
\hline 14:57:09 PM & 30 & 35 & 903 & 321.5 \\
\hline 15:00:09 PM & 30 & 35 & 899 & 355.5 \\
\hline
\end{tabular}

From the data in Table 2, the focal length The Solar irradiance for Setup A was measured and the tilt angle could be modified accordingly in order to attain high temperature inside the receiver. However, the highest temperature that was able to be reached by Setup A was only $485.25{ }^{\circ} \mathrm{C}$ at a solar irradiance of $912 \mathrm{w} / \mathrm{m}^{2}$. using a Seaward Solar Survey 200R solar irradiance meter. The meter was placed on the setup to measure the solar irradiance during time experiment which is from 11:00 am to 3:00 pm. The data obtained for the solar irradiance on the day of experiment is as shown in Figure 4.

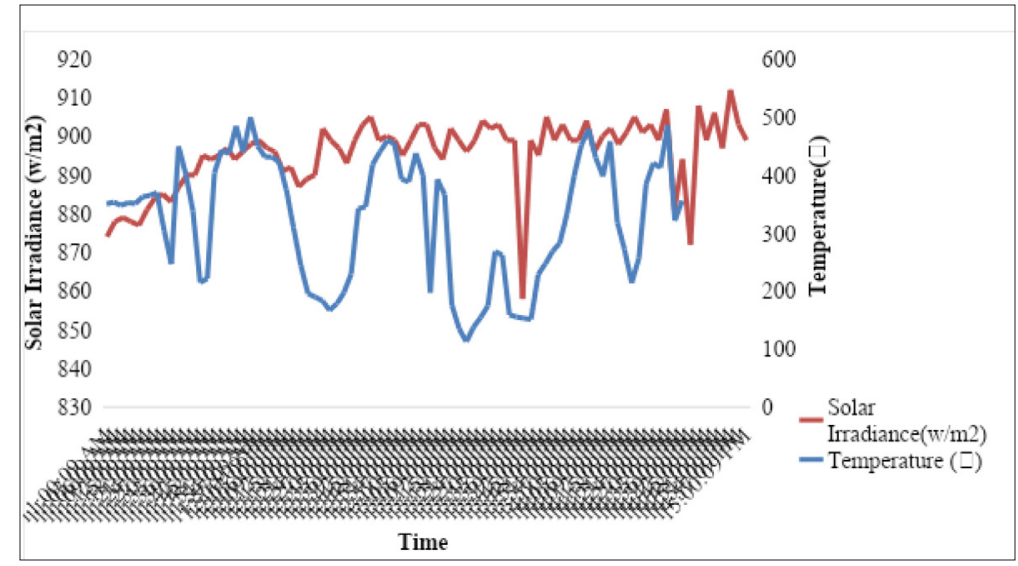

Figure 4: Effect of Solar irradiance and time variation on the internal temperature of the receiver for setup A 
Variation of solar intensity and internal temperature fluctuations with respect to time variation is shown in Figure 2. The highest temperature was reached at a Solar irradiance measurement of $912 \mathrm{w} / \mathrm{m}^{2}$ at around 12:05:00 noon. This shows that the solar irradiance of the sun was the highest at noon and the Fresnel lens is able to capture the light ray and convert it into the form of heat.

Regarding the effect of the solar irradiance, it is important to mention that the lowest peaks observed are mainly due to the clouds, which block the direct solar radiation, and the wind speed variation. The little fluctuations are essentially due to errors associated with the thermocouples considering that the variation of temperature at each time is low (Barbosa et al., 2016). From the results, it can be concluded that a difference in solar irradiance of approximately $46 \mathrm{~W} / \mathrm{m}^{2}$ leads to a significant loss of heat resulting in the temperature to decrease to $106.25^{\circ} \mathrm{C}$.

As for the effect of the time variation on the internal temperature can be interpreted by the movement of the sun. At noon, the sun is at the top directly above the Fresnel lens setup.

As for the Design for Setup B with a nontracking system installed, based on previous study by Cheng et al., 2016 the effect of the solar irradiance on the internal temperature is as shown in Figure 5.

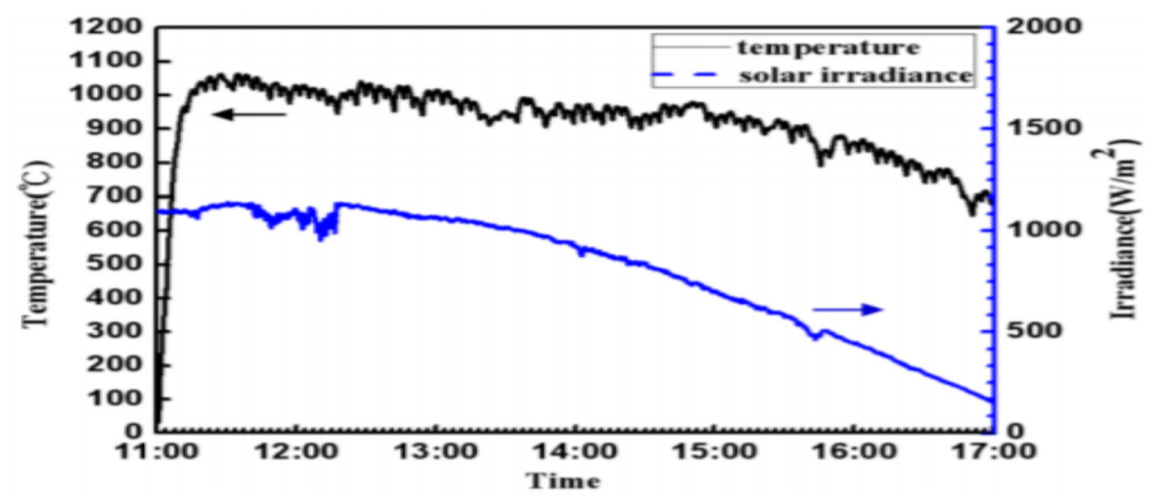

Figure 5: Effect of Solar irradiance and time variation on the internal temperature of the receiver for setup B (Cheng et al., 2016)

Based on a study by Cheng et al., (2016), tilt angles for the both setups (Setup A and Setup the slight temperature fluctuation in the temperature profile as seen in Figure 3 is due to the changing period from the mounted tracking device. However, about 16:00-17:00 in the afternoon, when the decrease in solar irradiation is only about 80 percent relative to midday, the decrease in the temperature curve is only about 35 percent due to the slight loss of heat and both decrease the temperature of the heating head. So even, when the solar irradiance is low, the temperature remains at a relatively higher temperature of around $650^{\circ} \mathrm{C}$.

It is observed experimental setting and the previous study, it has shown that the optimum B) are $35^{\circ}$. The increase in the tilt angle up to $45^{\circ}$ will cause the focal area to deviate from the initial position causing the focal length to become shorter causing the temperature to drop drastically. This is because the large tilt angle will lead to a large refraction and cause the light to diffuse causing the temperature to drop (Zheng, 2017). However for the setup B with a non-tracking system higher temperature of about $670^{\circ} \mathrm{C}$ can be attained meanwhile for setup A the highest temperature was only around $400^{\circ} \mathrm{C}$. This is because the ray of light is transmitted at one single point throughout the day instead of having heat being lost to the surrounding. 
Comparing the experimental results for Setup A and the literature result for Setup B, it is observed that the collector with a nontracking system installed is able to reach higher temperature internally when compared with the other concentrator that does not have any tracking system. In fact, the maximum temperature recorded in the receiver was only $485^{\circ} \mathrm{C}$ for Setup A. Meanwhile, the design of the segmented mirror system installed in setup B played a significant role to raise the temperature inside the receiver throughout the day. This confirms that a setup with a tracking system installed leads to a significant increase in system efficiency.

\section{Conclusion}

For Fresnel Lens solar concentrator, it is observed that by fixing the focal length to 35 $\mathrm{cm}$ and the tilt angle of the lens to be fixed to $30^{\circ}$ the maximum temperature that is obtained in the reactor can reach up to almost $500^{\circ} \mathrm{C}$. The Azimuth angle of the Sun on the noon of the experiment day was $103^{\circ}$ which contributed to the highest temperature reached. The maximum temperature that can be attained by a setup (Setup A) without any tracing system is only up to almost $500^{\circ} \mathrm{C}$ but improvement as suggest by previous study using a setup with a non-tracking system consisting of mirrors could enable it to attain higher temperature. In conclusion, the combination of Fresnel lens and mirror system is a unique tool for day-round concentration of sunlight in a specific location. This engineered device is useful over a day and for a whole year for many solar thermal and electrical applications without monitoring the sunlight using high cost trackers.

\section{Acknowledgements}

We are thankful to the support by the lecturers and students in Electronic \& Instrumentation Field at Faculty of Ocean Engineering, Technology and Informatics (FTKKI) in their technical assistance for this project. Our thanks and appreciations also go to our internship students from TU Delft for their time and support in completing this project.

\section{References}

Abdullah, W. S. W., Osman, M., Kadir, M. Z. A. A., \& Verayiah, R. (2019). The potential and status of renewable energy development in Malaysia. Energies, 12(12).

Alamoudi, A., Saaduddin, S. M., Munir, A. B., Muhammad-Sukki, F., Abu-Bakar, S. H., Yasin, S. H. M., Sellami, N. (2019). Using static concentrator technology to achieve global energy goals. Sustainability (Switzerland), 11(11), 1-22.

Barbosa1, J. L. (2016). Development of a solar concentrator with tracking system. Copernicus Publications.

Cheng. C. K. (2016). Biaxial-Type Concentrated Solar Tracking System with a Fresnel Lens for Solar-Thermal Applications.

Gupta, M., Dubey, A. K., Kumar, V., \& Mehta, D. S. (2019). Solar concentrator based multipurpose sunlight harvesting system without tracking. OSA Continuum, 2(3), 667.

Kannan, N., \& Vakeesan, D. (2016). Solar energy for future world: - A review. Renewable and Sustainable Energy Reviews, 62, 1092-110

Leutz, R., Suzuki, A., Akisawa, A., Kashiwagi, T., \& Toksoy, J. (2000). Developments and designs of solar engineering Fresnel lenses. Proceedings Symposium on Energy Engineering, 2, 759-765.

Madhugiri, G. A., \& Karale, S. R. (2012). High solar energy concentration with a Fresnel lens: A Review. International Journal of Modern Engineering Research (IJMER)

Mansour, A. F. (2005). Optical Properties of Fullerene/PMMA. International Journal of Polymeric Materials, pp. 227-235.

Mekhilef, S., Safari, A., Mustafa, W.E.S., Saidur, R.., Omar, R.., Younis, M. A. A. (2012) Solar energy in Malaysia: Current state and prospects. Renewable and Sustainable Energy Review, 16, 386-396. 
Peinado Gonzalo, A., Pliego Marugán, A., \& García Márquez, F. P. (2019). A review of the application performances of concentrated solar power systems. Applied Energy, 255, (March), 113893.

Ullah, I., \& Shin, S., (2014). Highly concentrated optical fiber-based daylighting systems for multi-floor office buildings. 72, 246-261.

Vu, N. H., \& Shin,. S. (2016). Optical fiber daylighting system combined with LED lighting and CPV based on stepped thickness waveguide for indoor lighting. Journal of the Optical Society of Korea, 20(4), 488-499.
Xie, W. T., Dai, Y. J., Wang, R. Z., \& Sumathy, K. (2011). Concentrated solar energy applications using Fresnel lenses: A review. Renewable and Sustainable Energy Reviews, 15(6), 2588-2606.

Zeaiter, J., Ahmad, M. N., Rooney, D., Samneh, B., \& Shammas, E. (2015). Design of an automated solar concentrator for the pyrolysis of scrap rubber. Energy Conversion and Management, 101, 118125.

Zheng, H. (2017). Solar Energy Desalination Technology. Amsterdam: John Feder. 
